\title{
Public Health Insurance System Reform and Its Impact on Health Service Utilization in Rural China: Evidence from CHNS 2000 and 2011
}

\author{
Xinxin Ma', Yangyang Cen ${ }^{2}$ \\ ${ }^{1}$ Institute of Economic Research, Hitotsubashi University, Tokyo, Japan \\ ${ }^{2}$ Graduate School of Economics, Hitotsubashi University, Tokyo, Japan \\ Email:maxx@ier.hit-u.ac.jp
}

How to cite this paper: Ma, X., \& Cen, Y. (2017). Public Health Insurance System Reform and Its Impact on Health Service Utilization in Rural China: Evidence from CHNS 2000 and 2011. Chinese Studies, 6, 85-107.

https://doi.org/10.4236/chnstd.2017.62009

Received: March 29, 2017

Accepted: May 20, 2017

Published: May 23, 2017

Copyright $\odot 2017$ by authors and Scientific Research Publishing Inc. This work is licensed under the Creative Commons Attribution International License (CC BY 4.0).

http://creativecommons.org/licenses/by/4.0/

\begin{abstract}
This study employs an empirical analysis to investigate the impact of the New Cooperative Medical Scheme (NCMS) on health service utilization in Chinese rural region using the 2000 and 2011 China Health and Nutrition Survey (CHNS) longitudinal survey data and Difference in Difference (DID) analysis method. The major conclusions are as follows. First, individual characteristic factors, enabling factors, health care need factors, and lifestyle factors affect health service utilization, which is consistent with Anderson model. Second, when controlled these factors based on Anderson model, the results indicate that the NCMS did not affect health service utilization (outpatient, inpatient, and health care examination) of individual when ill. Third, to consider the disparity of health care demand and supply, we also employ the analysis utilized the subsamples to take robustness checks. The results indicate that there is no difference statistically in health service utilization between the NCMS enrollment group and the non-enrollment group by age groups (16 - 49 aged group and 50 age and over group), income groups (High, Middle and Lowincome groups), and regional groups (East, West and Central Regions). Therefore, it can be said that the NCMS did not improve either health service utilization for patients or preventative health care for rural residents in China.
\end{abstract}

\section{Keywords}

New Cooperative Medical Scheme (NCMS), Health Service Utilization, Chinese Rural Region, Difference in Difference Analysis (DID), Anderson Model

\section{Introduction}

In China, with the implementation of one-child policy, the problem of popula- 
tion aging is becoming serious, therefore to construct social security system is an important issue for Chinese government. It is expected that public health insurance system as one kind of social security systems can play major role to address the high risk for high health care expenditure among the elderly group when they are ill. Moreover, in China, social security system is segregated by the rural and urban residents based on household registration system ("Hukou system") since 1950s. Because the public health insurance system differ by the rural and urban residents, and to compare with the urban residents, the public health insurance system changed dramatically for the rural resident from the planned economy period (1949-1977) to economic transition period (after 1978 until now), therefore this study focuses on the public health insurance system for rural residents.

To review the change of public health insurance in rural China, the Cooperative Medical Scheme (CMS) played a major role in preventing infectious diseases and providing primary health care. It was as a part of the people's commune systems in the planned economy period. However, after 1978, as the people's communes were eliminated and the rural household responsibility system was implemented, CMS enrollment rates decreased dramatically (from $90 \%$ in 1981 to merely $5 \%-10 \%$ in the 1990s) (Hsiao, 1984; Liu et al., 1995; Liu, 2004; Wagstaff \& Linedelow, 2008; Cheng et al., 2015). In addition, since the 1990s, the Chinese government enforced the reform of health care market, to move from planned systems to a competitive market. Therefore, total health care expenditures for individuals increased dramatically. As a result, a person with a serious illness risked poverty. In this way, health care inequality resulting from income inequality became a serious problem in China (Ma, 2015). To address this social problem, in 2003 the Chinese government introduced a new public health insurance scheme in rural regions-the New Cooperative Medical Scheme (NCMS). Enrollment in NCMS is optional, and it covers all residents within the rural registrations. Although the central and local governments support the NCMS financial foundation, participants have to pay medical insurance premiums. Since insurance funds are insufficient, resulting in lower government repayment accounts, the majority of health care expenditures are paid by the patients themselves. Therefore, it is thought that even if a rural household participates in the NCMS, they may still not access health services when required because they are worried that the cost of obtaining health services could drive the household into poverty. This study employs an empirical analysis to investigate the impact of NCMS on health service utilization for rural residents.

To consider the issue ${ }^{1}$, Wagstaff et al. (2009), Shi et al. (2010), You and Kobayashi (2011), Lu et al. (2012), Li and Zhang (2013), Lu and Zhang (2013), Li et

\footnotetext{
${ }^{1}$ Worldwide, there have been numerous empirical studies on the impacts of public health care insurance reform on health services utilization. Notable examples are Currie and Gruber (1996a, 1996b, 1997), Decker and Rember (2004), Currie et al. (2008), Card et al. (2008) and Finkelstein and McKnight (2008). In these studies, micro-data based on social experiments by RAND are used to estimate the impacts of Medicare and Medicaid performed in the U.S. For empirical studies on other developing countries, please see Jowett et al. (2004) and Sepehri et al. (2006) for Vietnam, Panopoulu and Velez (2001), Trujillo et al. (2005) for Columbia, and Gakidou et al. (2006) for Mexico.
} 
al. (2014) used cross-section data to investigate the impact of NCMS on health service utilization (i.e., the probability of access to a hospital and health care expenditures when needed). In addition, Wagstaff and Lindelow (2008), Lei and Lin (2009), Cheng et al. (2015), Ma (2016) used panel data to address the heterogeneity problem (Appendix Table A1) ${ }^{2}$. However, the estimated results were not consistent among the different measurement methods and datasets, and some problems remain unanswered as follows. First, although DID (difference in difference) analysis is an appropriate method for policy assessment, which is often used in empirical studies, this method is rarely used for this issue in China. Second, in most previous studies, the analysis period is short-term. For example, the analysis period in Wagstaff and Lindelow (2008), Wagstaff et al. (2009), Lei and Lin (2009), Shi et al. (2010), You and Kobayashi (2011), Lu et al. (2012), Li and Zhang (2013), Li et al. (2014), Lei and Lin (2009), Cheng et al. (2015), Ma (2016) is around the period from 2000 and 2006, therefore the impact of NCMS on health service utilization is not clear in the long-term. Third, it is thought that the demand of health care may differ by individual characteristics. For example, because the health status is worse for the elderly group than for younger and middle-age groups, the demand of health care might be greater for elderly groups than the other age groups.

As described above, although a part of the health service fee may be paid by public health insurance, the patient must pay a set of health service fees by themselves or their household, therefore there may exist a liquidity constraint problem, which causes a disparity of health service utilization by low-, middle-, and high-income groups. Moreover, because the supply of health service differs by region, and the types of disease and life-style differ by regions, there may exist a regional disparity of health services utilization. For example, based on the data in China Statistics Year Book 2012 (NBS, 2013), in 2011 the doctor numbers per thousand populations are 1.60 for the East Region, 1.29 for the Central Region, 1.30 for the West Region in rural China; the beds available per thousand populations are 3.23 for the East Region, 2.83 for the Central Region, and 3.32 for the West Region in rural China. In previous studies, these group disparities are not analyzed.

In this study, using two waves (2000 and 2011) of the China Health and Nutrition Survey (CHNS), we investigate the impact of NCMS on health service utilization: the probability of accessing a hospital (inpatient and outpatient) and the probability of receiving a health examination. This study also uses subsamples to analyze the disparity of NCMS impacts by groups. Because we utilized long-term panel data (from 2000 to 2011), the policy effect can be analyzed in the long-term.

This study is structured as follows: Section 2 introduces public health insurance reform in rural China as the research background. Section 3 is the framework of the empirical analysis, including models and datasets; Section 4 presents estimation results; and Section 5 gives a summary of the conclusions.

${ }^{2}$ For the details of survey on the issue, please refer Ma (2015) at page 232-233. 


\section{Research Background: Reform of Public Health Insurance in Rural China}

\subsection{The Background of Reform of Public Health Insurance in Rural China}

During its planned economy period, the Chinese government promoted the establishment and implementation of a social security system based on socialist principles. Specifically, in the urban regions Labor Medical Insurance (LMI) was introduced in the 1950s. The LMI covered the workers in SOEs or Collective-owned Enterprises (COEs), and Government Medical Insurance (GMI), covered the workers in government or public organizations (Shiye Danwei; e.g., schools, hospitals, and research institutes). These medical insurance systems also covered employees' family members. In addition, in the rural regions the Cooperative Medical System (CMS) which was a community mutual assistance system, was promoted in the 1960s. CMS was implemented along with the dissemination of People's Communes, an administrative level of the Communist Party which operated and managed the CMS in China's rural regions. Because the LMI, GMI, and CMS covered the entire population of China, it can be said that the universal health insurance system was established in China during the planned economy period.

Since 1978, however, the Chinese government has been transforming itself from a closed centralized planned economy to an open market economy. China's public medical insurance systems underwent significant changes as part of this transition. Alongside the reform of Labor Medical Insurance (LMI) in the urban regions, the government re-established a new public health insurance system in the rural regions. In the rural regions, the CMS enrollment rates decreased dramatically (from 90\% in 1981 to merely 5\% in the 1990s) with the implementation of the "Household Contract Production System" (Jiating Liangchan Chengbao Zerenzhi). This was caused by the dramatic reduction in the number of People's Communes (Liu et al., 1995; Wagstaff \& Linedelow, 2008; Cheng et al., 2015; Ma, 2015, 2016). In addition, since the 1990s, the Chinese government has been enforcing public hospital management reforms by converting Chinese health service systems from the planned economy system to the market economy system. Along with the reform of public hospital management, the government subsidies to public hospitals were greatly reduced. The public hospitals had to be operated as profitable firms, the public hospitals began to promote the usage of more expensive drugs and health services in order to gain more profits. Thus the out-of-pocket health care costs for patients increased substantially. As a result, there is a possibility that the individuals with a serious illnesses may fall into poverty because not only do these patients have to pay the health care fees by themselves but also they need to pay more for health care which they need. Therefore, the inequality in health care utilization caused by the income gap became a serious social problem. To address the problem, in 2003 the Chinese government introduced a new public health insurance schemethe NCMS, in rural regions. 


\subsection{The Main Features of NCMS}

The NCMS covers the whole population with rural registration. The main features of the NCMS are as follows. First, even though the enrollment into the NCMS is voluntary, the central and local governments promote participation in the scheme positively. Second, the administration must be at county level, and be controlled by province level government. Third, the NCMS must prioritize serious illness, receiving funding from both central and local government and individuals. Because the financial situation differs among the regions, the insurance funding of NCMS differs by regional groups. Moreover, because insurance funds are insufficient, resulting in lower government repayment accounts, a majority of health care expenditures (the whole of outpatient, a majority of inpatient) are paid by the patients themselves. Fourth, the participation unit is the household (or family) for the NCMS. The NCMS requires that all family members participate in the scheme.

\subsection{The Implementation Situation of NCMS}

The NCMS has witnessed a rapid expansion in coverage since the government introduced it in 2003. The data based on China Statistics Year Book 2015 (NBS, 2016) shows that the enrollment rates of NCMS increased from $74.0 \%$ in 2003 to $97.5 \%$ in 2011, and $98.9 \%$ in 2014. It seems that the universal health insurance system was re-established in the 2000s in the rural regions.

What about the reimbursements and benefits from the NCMS? Lei and Lin (2009) describe four main models of how NCMS is implemented throughout China. The first model is used in $65.26 \%$ of counties in rural regions. Inpatient services are reimbursed according to a formula, while outpatient services, including preventive care, are paid for through a medical savings account. Each household has its own medical savings account, with household members depositing their contributions into this account and then the health care service fee is paid from it. Only household members are entitled to the funds in the account, which is used mainly for outpatient services. The second model is used in $6.7 \%$ of the rural regions. The inpatient reimbursement policy is the same as in the first model; the main difference is in outpatient reimbursement. Under this model, there is no medical savings account designated for outpatient services and preventive-care usage. These services are reimbursed according to a certain formula through collective funds, usually with no deductible and no reimbursement cap. The local rural region (countries) usually provide one free physical check-up per year for those who participate in the NCMS but do not use any medical services that require NCMS reimbursement within that year. The third model is used in $11.17 \%$ of counties in rural regions, it reimburses inpatient services as well as outpatient services for serious diseases, with separate deductibles and reimbursement caps. The fourth model is used by $16.87 \%$ of all counties in rural regions, the NCMS reimburses inpatient services but not outpatient services. The models differ in the type of reimbursements. The common feature in these models is that a set of health care fees has to be paid by patient themselves 
or their family. The data based on 2008 China Health Care Service Survey shows that the percentage of the health care fee paid by the individual (or household) is $56.0 \%$ for rural residents, whereas it is $31.8 \%-32.8 \%$ for urban residents. Thus, it is thought the liquidity constraint problem is more serious for rural residents than that for urban residents. The low-income patient may not be able to utilize the health service which they need for rural residents.

The government has promoted the implementation of NCMS in rural regions and the coverage of NCMS increased greatly. However, because the out-of pocket payments are still too high for rural residents to afford, it is unlikely that the implementation of NCMS actually improves the health care service utilization for many poorer rural patients. This study employs empirical analysis to explore this problem.

\section{Methodology}

\subsection{Models}

It is thought the status before and after NCMS implementation is perhaps different, and there may be unobserved attitudinal differences between the enrollment group and no-enrollment group. To address these problems, the DID method is utilized, it is expressed in Equation (1)

$$
y_{i t}^{*}=a_{t}+\gamma_{1} \text { Treatment }_{i t}+\gamma_{2} \text { Year }_{t}+\gamma_{3} \text { DID }_{i t}+\gamma_{4} X_{i t}+\varepsilon_{i t}
$$

In Equation (1), $i$ denotes individuals; $t$ denotes NCMS survey year (here, 2000, 2011); $P\left(y_{i t}=1\right)$ indicates the dependent variable (equal to 1 if the individual has gone to the hospital (inpatient or outpatient) when ill or has received a health examination, equal to 0 if not; equal to 1 if the individual has received a health examination in the last year, equal to 0 if not), $y_{i}$ is a continuous but unobservable latent variable; $\alpha$ is a constant, $\varepsilon_{i t}$ is the usually error term. Treatment is treatment group dummy. Using CHNS panel data, the treatment group and control group are conducted as follows. The control group is the group which has not participated in the NCMS in both 2000 when NCMS has not been implemented and in 2011 when NCMS has been implemented. The treatment group is the group which has not participated to NCMS in 2000, but has participated in the NCMS in 2011. Year is year dummy when NCMS has been implemented (here, 2011year dummy). DID is an interaction of treatment group dummy variable and year dummy variable. $X$ are factors affecting the health care service utilization. $\gamma_{1}$, $\gamma_{2}, \gamma_{3}, \gamma_{4}$ are estimated coefficients. When $\gamma_{3}$ are positively statistically significant, it indicates that compared with the group who has not participated in the NCMS, the probability of going to hospital (outpatient or inpatient) or the probability of receiving a health examination is higher in the enrollment group.

\subsection{Data}

This study employs two waves (2000 and 2011) of CHNS survey data. CHNS is a nationwide longitudinal survey conducted by the Carolina Population Center at the University of North Carolina and the National Institute for Nutrition and 
Health (NINH, former National Institute of Nutrition and Food Safety) at the Chinese Center for Disease Control and Prevention (CCDC). The survey was conducted by an international team of researchers whose backgrounds include nutrition, public health, economics, sociology, Chinese studies, and demography. The survey took place over a 7-day period using a multistage, random cluster process to draw a sample of about 7200 households with over 30,000 individuals in 15 provinces and municipal cities that vary substantially in geography, economic development, public resources, and health indicators. This study utilizes 11 provinces samples which are covered in both 2000 and 2011. They are Beijing, Liaoning, Heilongjiang, Shanghai, Jiangsu, Shandong, Hernan, Hubei, Hunan, Guangxi, and Guizhou.

The independent variables of health service utilization are binary variables (equal to 1 if the individual has gone to the hospital (inpatient or outpatient) when ill and equal to 0 if not; equal to 1 if the individual has received a health examination in the last year, equal to 0 if not).

Andersen and Newman (1973), and Andersen (1995) point out that four factors affect health care seeking behavior: they are individual characteristic factors, enabling factors, health care demand factors, and life-style factors. Individual characteristic factors may be defined as individual socio-demographic factors such as education, age, gender, and marital status ${ }^{3}$. Independent variable settings based on the Anderson model are as follows.

First, age, education dummy, and gender dummy are used as an index of "individual characteristic factors". Based on Grossman's health capital model (Grossman, 1972), it is thought the probability of health service utilization (or seeking the health service) is higher in both the elderly group and higher education group. A gender dummy is used to control the gender gaps in the demand of health care.

Second, in previous studies health insurance, income, health care supply situation are used as an index of "enabling factors". NCMS is a binary dummy. The participants' income is reported as the household income per capita, which divides the total household income by household size. Here, income is composed of agriculture revenue, farming revenue, fruit revenue, non-agricultural revenue, and transfer income. Province dummies are utilized to control the regional disparity of health care supply status.

Third, self-reported health status, a hypertension dummy, and a diabetes dummy are utilized as index of health care demand factors. It is thought that the probability will be higher in the groups with hypertensive or diabetic disease, and in the group who reported their health status to be poor.

Fourth, smoking status (equal to 1 if the individual is smoking in survey year or has smoked in the past, equal to 0 if not), drinking frequency dummy, doing healthy exercise (equal 1 if the individual is doing health exercise in the survey year, equal to 0 if not), living environment variables are set as an index of

${ }^{3}$ You and Kobayashi (2011) and Li and Zhang (2013) utilized Anderson's behavior model to employ empirical studies on health service utilization, but they do not analyze the health insurance system. Although Ma $(2015,2016)$ utilized the model to analyze the impact of public health insurance on health service utilization, the analysis period is limited, from 2000 to 2006. 
"life-style factors". Living hygiene environment variables are composed of water (drink water in home or out of home), toilet (in home or out home), waste status (whether or not there is waste near the house).

The statistical description of variables is shown in Table 1 . The mean value of variables is different by the NCMS enrollment group and non-enrollment group. It is indicated that the individual characteristics are different by groups, and this disparity of individual characteristics may influence the participation in the NCMS and health service utilization. These heterogeneity problems should be considered in the empirical study.

\section{Econometric Analysis Results}

\subsection{The Impact of NCMS on Health Service Utilization}

To investigate the impact of NCMS on health service utilization, an empirical analysis is employed. To address the heterogeneity problem, the DID method is utilized. The results are summarized in Table 2. The main findings are as follows.

First, the coefficients of DID items in Estimations 1) (both outpatient and inpatient), 2) (outpatient), 3) (inpatient) are not statistically significant; moreover, the coefficients of DID items in Estimations 4) (health examination) are negatively statistically significant. It is shown that there is no difference of health service utilization (both outpatient and inpatient, outpatient, inpatient) between the NCMS enrollment group and the non-enrollment group, and the probability of inpatient and receiving the health examination are lower for NCMS enrollment group than for the NCMS non-enrollment group. These results indicated that generally, when the heterogeneity problem and group selection bias problems are considered, NCMS did not increase the probability of patients access to hospital (outpatient or inpatient) and health prevention (to receive health examination) after the NCMS system implementation over the long-term (from 2003 to 2011). The results of Estimations (1), (2) and (3) are consistent with Wagstaff et al. (2009) and Ma $(2015,2016)$.

However, the results of Estimation (4) are not consistent with the previous studies. Concretely, Wagstaff et al. (2009) and Ma $(2015,2016)$ point out that the NCMS positively affects the probability of receiving a health examination, whereas the result in this study indicates that the NCMS did not affect the utilization of health examinations. The main reason are considered as the following. First, it may be that the analysis periods are different in these studies. For example, the analyzed period is from 2000 to 2004 or 2006 in Wagstaff et al. (2009) and Ma $(2015,2016)$, whereas it is from 2000 to 2011 in this study. In the prior implementation period of the NCMS, in order to promote the participation to the NCMS for a long time, some local government usually provide one free health examination per year for those who participate in the NCMS but do not utilize any health services in that year. However, along with the increase of participation rate of the NCMS, the free health examination services have reduced. Second, the condition of receiving free health examination per year is that the 
Table 1. Statistics description.

\begin{tabular}{|c|c|c|c|c|c|c|}
\hline & \multicolumn{2}{|c|}{ Total samples } & \multicolumn{2}{|c|}{ Non-enrollment group } & \multicolumn{2}{|c|}{ Enrollment group } \\
\hline & mean & S.D. & mean & S.D. & mean & S.D. \\
\hline \multicolumn{7}{|l|}{ Year } \\
\hline 2000 & 0.2198 & 0.4141 & 0.6978 & 0.4593 & 0.0230 & 0.1498 \\
\hline 2011 & 0.7802 & 0.4141 & 0.3022 & 0.4593 & 0.9770 & 0.1498 \\
\hline \multicolumn{7}{|l|}{ Predisposing factors } \\
\hline \multicolumn{7}{|l|}{ Age category } \\
\hline age $0-20$ & 0.2153 & 0.4110 & 0.2953 & 0.4562 & 0.1825 & 0.3863 \\
\hline age $20-29$ & 0.0966 & 0.2954 & 0.1506 & 0.3577 & 0.0751 & 0.2636 \\
\hline age $20-39$ & 0.1203 & 0.3253 & 0.1374 & 0.3443 & 0.1127 & 0.3163 \\
\hline age $30-49$ & 0.1882 & 0.3909 & 0.1426 & 0.3497 & 0.2061 & 0.4045 \\
\hline age $40-59$ & 0.1649 & 0.3712 & 0.1058 & 0.3077 & 0.1896 & 0.3920 \\
\hline age $60-69$ & 0.1290 & 0.3353 & 0.0850 & 0.2789 & 0.1471 & 0.3543 \\
\hline age70 and over & 0.0857 & 0.2799 & 0.0833 & 0.2763 & 0.0869 & 0.2816 \\
\hline \multicolumn{7}{|l|}{ Education category } \\
\hline no schooling & 0.3127 & 0.4636 & 0.2719 & 0.4450 & 0.3281 & 0.4695 \\
\hline primary school & 0.2359 & 0.4246 & 0.2369 & 0.4252 & 0.2364 & 0.4249 \\
\hline junior high school & 0.3353 & 0.4721 & 0.3420 & 0.4745 & 0.3323 & 0.4711 \\
\hline senior high school & 0.0824 & 0.2751 & 0.1025 & 0.3033 & 0.0742 & 0.2622 \\
\hline vocational school & 0.0205 & 0.1418 & 0.0273 & 0.1629 & 0.0181 & 0.1331 \\
\hline college and over & 0.0132 & 0.1141 & 0.0194 & 0.1382 & 0.0109 & 0.1041 \\
\hline
\end{tabular}

\section{Health care} need factors

Self-reported health Status

$\begin{array}{ccccccc}\text { very good } & 0.1469 & 0.3541 & 0.1533 & 0.3604 & 0.1452 & 0.3523 \\ \text { good } & 0.3807 & 0.4856 & 0.4567 & 0.4983 & 0.3552 & 0.4786 \\ \text { generally } & 0.3966 & 0.4892 & 0.3125 & 0.4636 & 0.4242 & 0.4943 \\ \text { bad } & 0.0635 & 0.2438 & 0.0743 & 0.2623 & 0.0601 & 0.2377 \\ \text { very bad } & 0.0083 & 0.0906 & 0.0021 & 0.0462 & 0.0103 & 0.1010 \\ \text { don't know } & 0.0040 & 0.0637 & 0.0011 & 0.0327 & 0.0050 & 0.0710 \\ \text { Hypertension } & 0.1294 & 0.5366 & 0.0939 & 0.4435 & 0.1408 & 0.5636 \\ \text { Diabetes } & 0.0392 & 0.4530 & 0.0312 & 0.3262 & 0.0418 & 0.4866\end{array}$

\section{Enabling factors}

$\begin{array}{ccccccc}\text { Regions } & & & & & & \\ \text { Beijing } & 0.0263 & 0.1600 & 0.0160 & 0.1253 & 0.0307 & 0.1725 \\ \text { Liaoning } & 0.0714 & 0.2576 & 0.0923 & 0.2895 & 0.0633 & 0.2436 \\ \text { Heilongjiang } & 0.0958 & 0.2943 & 0.1128 & 0.3164 & 0.0892 & 0.2851\end{array}$


Continued

\begin{tabular}{|c|c|c|c|c|c|c|}
\hline Shanghai & 0.0112 & 0.1052 & 0.0219 & 0.1463 & 0.0071 & 0.0837 \\
\hline Jiangsu & 0.0857 & 0.2799 & 0.0920 & 0.2890 & 0.0819 & 0.2742 \\
\hline Shandong & 0.0763 & 0.2656 & 0.0673 & 0.2506 & 0.0797 & 0.2708 \\
\hline Hernan & 0.1282 & 0.3343 & 0.1506 & 0.3577 & 0.1178 & 0.3224 \\
\hline Hubei & 0.0975 & 0.2967 & 0.1266 & 0.3326 & 0.0868 & 0.2816 \\
\hline Hunan & 0.0896 & 0.2856 & 0.0812 & 0.2732 & 0.0910 & 0.2876 \\
\hline Guangxi & 0.1345 & 0.3413 & 0.0867 & 0.2815 & 0.1549 & 0.3618 \\
\hline Guizhou & 0.1137 & 0.3175 & 0.1176 & 0.3222 & 0.1134 & 0.3171 \\
\hline Chongqing & 0.0698 & 0.2546 & 0.0350 & 0.1839 & 0.0842 & 0.2777 \\
\hline $\begin{array}{l}\text { Household income } \\
\text { (Yuan) }\end{array}$ & 13338 & 20871 & 8386 & 12822 & 15160 & 22860 \\
\hline \multicolumn{7}{|l|}{ Life-style factors } \\
\hline Smoking & 0.3087 & 0.4713 & 0.3039 & 0.4986 & 0.3101 & 0.4626 \\
\hline not drinking & 0.6833 & 0.4652 & 0.6732 & 0.4692 & 0.6861 & 0.4641 \\
\hline drink everyday & 0.1048 & 0.3063 & 0.1016 & 0.3022 & 0.1057 & 0.3075 \\
\hline 3 - 4 times weekly & 0.0406 & 0.1974 & 0.0432 & 0.2033 & 0.0398 & 0.1956 \\
\hline 2 - 3 times weekly & 0.0702 & 0.2555 & 0.0832 & 0.2762 & 0.0664 & 0.2489 \\
\hline 1 - 2 times weekly & 0.0593 & 0.2362 & 0.0611 & 0.2395 & 0.0590 & 0.2356 \\
\hline $1-2$ times monthly & 0.0386 & 0.1928 & 0.0363 & 0.1871 & 0.0395 & 0.1949 \\
\hline less one time monthly & 0.0031 & 0.0552 & 0.0016 & 0.0397 & 0.0035 & 0.0594 \\
\hline Don't know & 0.1460 & 0.3534 & 0.1878 & 0.3903 & 0.1300 & 0.3360 \\
\hline Health exercise & 0.5345 & 0.4988 & 0.4594 & 0.4984 & 0.5638 & 0.4960 \\
\hline $\begin{array}{c}\text { Drink water inside } \\
\text { the home }\end{array}$ & 0.3878 & 0.4873 & 0.3139 & 0.4642 & 0.4187 & 0.4934 \\
\hline Toilet inside the home & 0.3434 & 0.4749 & 0.3910 & 0.4880 & 0.3249 & 0.4684 \\
\hline $\begin{array}{c}\text { Waste nearby the } \\
\text { home }\end{array}$ & 0.6833 & 0.4652 & 0.6732 & 0.4692 & 0.6861 & 0.4641 \\
\hline Samples & 10191 & & 2960 & & 7231 & \\
\hline
\end{tabular}

Data source: Calculated based on CHNS2011.

individual is healthy and he has not receive the health care survey-either outpatient or inpatient-which cause to the reimbursement account is zero. When the individual's healthy status became worse and has to go to the hospital or the clinic, the probability of receiving free health examination decrease. Third, because the individual who participates the NCMS can receive medical expense reimbursement when he utilized health care service. With the rise of reimbursement account recently, the effort to receive the health examination for early detection of illness may became decreased. Thus, the results using CHNS2000 and CHNS2011 showed the positive effect of the NCMS on receiving health examination recently disappeared. 
Table 2. (a) The impact of NCMS on health service utilization (1) Both outpatient and outpatient, (2) Outpatient (total samples); (b) The impact of NCMS on health service utilization (3) Inpatient, (4) Health examination (total samples).

(a)

\begin{tabular}{|c|c|c|c|c|}
\hline & \multicolumn{2}{|c|}{ (1) Both outpatient and inpatient } & \multicolumn{2}{|c|}{ (2) Outpatient } \\
\hline & coeff. $(\mathrm{dy} / \mathrm{dx})$ & $z$-value & coeff. $(\mathrm{dy} / \mathrm{dx})$ & z-value \\
\hline Treatment & 0.1689 & 0.68 & 0.1973 & 0.79 \\
\hline Year & $0.2607^{\star *}$ & 2.39 & $0.3807^{\star * *}$ & 3.54 \\
\hline DID & -0.2286 & -0.88 & -0.2459 & -0.95 \\
\hline \multicolumn{5}{|l|}{$\begin{array}{l}\text { Individual } \\
\text { characteristic } \\
\text { factors }\end{array}$} \\
\hline \multicolumn{5}{|l|}{ Age category } \\
\hline age $16-19$ & -0.4898 & -1.43 & -0.4043 & -1.17 \\
\hline age $20-29$ & $-0.3855^{* * *}$ & -2.84 & $-0.3226^{\star *}$ & -2.39 \\
\hline age $30-39$ & $-0.3906^{* * *}$ & -3.38 & $-0.2763^{* *}$ & -2.43 \\
\hline age $40-49$ & $-0.2820^{* * *}$ & -2.7 & $-0.2063^{\star *}$ & -2.00 \\
\hline age $50-49$ & -0.0990 & -1.00 & -0.0103 & -0.11 \\
\hline age $60-69$ & -0.0718 & -0.72 & 0.0288 & 0.29 \\
\hline \multicolumn{5}{|l|}{ Education category } \\
\hline no schooling & $0.5693^{\star *}$ & 2.30 & $0.6349^{* * *}$ & 2.68 \\
\hline primary school & $0.4241^{*}$ & 1.72 & $0.4802^{* *}$ & 2.04 \\
\hline junior high school & $0.4227^{\star}$ & 1.75 & $0.4051^{*}$ & 1.75 \\
\hline senior high school & 0.1932 & 0.76 & 0.2438 & 1.01 \\
\hline vocational school & 0.4102 & 1.45 & 0.3216 & 1.17 \\
\hline \multicolumn{5}{|l|}{$\begin{array}{l}\text { Health care } \\
\text { demand factors }\end{array}$} \\
\hline \multicolumn{5}{|l|}{ Self-reported health } \\
\hline \multicolumn{5}{|l|}{ Status } \\
\hline very good & 0.2798 & 0.55 & 0.4554 & 0.87 \\
\hline good & 0.4038 & 0.80 & 0.5125 & 0.99 \\
\hline generally & 0.4595 & 0.91 & 0.5526 & 1.06 \\
\hline bad & $0.8698^{*}$ & 1.69 & $0.8892^{*}$ & 1.69 \\
\hline very bad & 0.7594 & 1.30 & 0.7126 & 1.20 \\
\hline Hypertension & $0.0866^{\star *}$ & 2.12 & $0.1245^{\star * *}$ & 3.21 \\
\hline Diabetes & 0.0364 & 0.81 & 0.0294 & 0.69 \\
\hline Enabling factors & & & & \\
\hline
\end{tabular}




\section{Continued}

Regions

\begin{tabular}{|c|c|c|c|c|}
\hline Beijing & 0.1631 & 1.05 & 0.1373 & 0.92 \\
\hline Liaoning & $-0.5636^{* * *}$ & -4.39 & $-0.6662^{* * *}$ & -5.42 \\
\hline Heilongjiang & $-0.7752^{\star * *}$ & -5.94 & $-0.8647^{\star * *}$ & -7.01 \\
\hline Shanghai & 0.2023 & 1.18 & 0.1392 & 0.84 \\
\hline Jiangsu & $-0.3633^{* * *}$ & -3.27 & $-0.4756^{\star * *}$ & -4.46 \\
\hline Shandong & $-0.5734^{* * *}$ & -4.53 & $-0.7049^{* * *}$ & -5.75 \\
\hline Hernan & -0.1440 & -1.36 & $-0.2988^{\star * *}$ & -2.92 \\
\hline Hubei & $-0.5846^{* * *}$ & -5.02 & $-0.7652^{\star * *}$ & -6.72 \\
\hline Hunan & $-0.4300^{* * *}$ & -3.63 & $-0.6037^{\star * *}$ & -5.21 \\
\hline Guangxi & $-0.2744^{* * *}$ & -2.72 & $-0.3431^{* * *}$ & -3.57 \\
\hline Guizhou & $-0.5637^{\star \star *}$ & -5.13 & $-0.7262^{\star * \star}$ & -6.82 \\
\hline usehold income & $-4.69 \mathrm{E}-07$ & -0.35 & $-1.72 \mathrm{E}-06$ & -1.18 \\
\hline -style factors & & & & \\
\hline Smoking & 0.0202 & 0.34 & -0.0028 & -0.05 \\
\hline Drinking & & & & \\
\hline not drinking & -0.1949 & -0.44 & $-0.9500^{\star *}$ & -2.39 \\
\hline everyday & -0.3693 & -0.82 & $-1.0993^{\star * *}$ & -2.73 \\
\hline 4 times weekly & -0.1329 & -0.29 & $-0.9526^{* *}$ & -2.31 \\
\hline 2 times weekly & -0.2239 & -0.49 & $-0.9583^{* *}$ & -2.36 \\
\hline 2 times monthly & -0.3116 & -0.68 & $-1.0192^{\star \star}$ & -2.50 \\
\hline $\begin{array}{l}\text { less one time } \\
\text { monthly }\end{array}$ & -0.2765 & -0.60 & $-0.9182^{\star \star}$ & -2.23 \\
\hline Health exercise & 0.10181 & 0.89 & 0.1626 & 1.48 \\
\hline $\begin{array}{l}\text { ink water inside } \\
\text { the home }\end{array}$ & -0.0396 & -0.72 & -0.0409 & -0.76 \\
\hline $\begin{array}{l}\text { oilet inside the } \\
\text { home }\end{array}$ & 0.0350 & 0.57 & 0.0470 & 0.79 \\
\hline $\begin{array}{l}\text { aste nearby the } \\
\text { home }\end{array}$ & -0.0846 & -1.54 & -0.0147 & -0.28 \\
\hline constant & $-1.5641^{\star *}$ & -2.14 & -0.9855 & -1.39 \\
\hline umbers of obs. & 5550 & & 5569 & \\
\hline Log likelihood & -1637.4693 & & -1752.925 & \\
\hline $\operatorname{LR~chi~}^{2}(42)$ & 276.01 & & 367.88 & \\
\hline Prob > chi 2 & 0.0000 & & 0.0000 & \\
\hline Pseudo R2 & 0.0777 & & 0.0950 & \\
\hline
\end{tabular}

Notes: $1 .{ }^{*},{ }^{* *},{ }^{* * *}$ : statistical significant in $10 \%, 5 \%, 1 \%$ level. 2 . Coefficient values are estimated marginal effect $(\mathrm{dy} / \mathrm{dx})$ values. 3. Reference group are the age 70 and over, the college and over, don't know (health status), Chongqing, don't know (drinking status) groups. Data source: Calculated based on CHNS2000 and 2011. 
(b)

\begin{tabular}{ccccc}
\hline & \multicolumn{2}{c}{ (3) Inpatient } & \multicolumn{2}{c}{$(4)$ Health examination } \\
\cline { 2 - 5 } & coeff. $(\mathrm{dy} / \mathrm{dx})$ & z-value & coeff. $(\mathrm{dy} / \mathrm{dx})$ & z-value \\
\hline Treatment & -3.04480 & -0.02 & 0.5340 & 1.15 \\
Year & $0.6580^{* * *}$ & 2.58 & $1.2034^{* * *}$ & 5.41 \\
DID & 2.6509 & 0.02 & $-0.8178^{*}$ & -1.7
\end{tabular}

Predisposing

factors

Age category

age20-29

$-0.5782^{*}$

$-1.86$

$-0.6350^{* * *}$

$-3.41$

age30-39

$-0.4325^{*}$

$-1.88$

$-0.4431^{\star * *}$

$-2.91$

age 40-49

$-0.4664^{\star *}$

$-2.22$

$-0.4426^{* * *}$

$-3.16$

age 50-59

$-0.1803$

$-0.95$

$-0.3573^{* * *}$

$-2.67$

age60-69

$-0.1496$

$-0.79$

$-0.1904$

$-1.44$

Education category

$\begin{array}{cc}\text { not enrollment } & -0.0877 \\ \text { primary school } & 0.0636 \\ \text { junior high school } & 0.0362 \\ \text { senior high school } & -0.1835\end{array}$

$-0.20$

$-0.5554^{* * *} \quad-2.64$

0.15

$-0.5169^{* *}$

$-2.50$

senior high schoo

0.08

$-0.4154^{* \star}$

$-2.14$

$-0.39$

$-0.5250^{\star *}$

$-2.48$

Health care

demand factors

Self-reported

health Status

very good

$-0.7282$

$-1.39$

0.4513

0.88

good

$-0.6270$

$-1.26$

0.3259

0.64

generally

$-0.4121$

$-0.83$

0.2547

0.50

bad

$-0.2940$

$-0.57$

0.4485

0.86

Hypertension

0.0853

1.09

$0.1412^{\star * *}$

2.66

Diabetes

0.0061

0.07

$-0.0874$

$-1.17$

\section{Enabling factors}

Regions

$\begin{array}{cc}\text { Liaoning } & 0.0123 \\ \text { Heilongjiang } & 0.0174 \\ \text { Shanghai } & -0.0177 \\ \text { Jiangsu } & 0.1443 \\ \text { Shandong } & 0.2947 \\ \text { Hernan } & 0.2600 \\ \text { Hubei } & 0.1668\end{array}$

0.04
0.06
-0.04
0.50
1.02
0.94
0.57

$-0.6226^{* * *}$

$-3.04$

$-0.5513^{* * *}$

$-3.06$

0.0177

0.2921

1.40

$-0.0818$

$-0.56$

0.2947

$-0.5830^{* * *}$

$-3.04$

0.2600

$-0.4038^{\star *}$

$-2.54$

0.1668

$0.3673^{\star * *}$

2.80 
Continued

\begin{tabular}{|c|c|c|c|c|}
\hline Hunan & $0.4738^{*}$ & 1.74 & $-0.3673^{\star *}$ & -2.14 \\
\hline Guangxi & 0.2210 & 0.80 & $-0.2488^{*}$ & -1.76 \\
\hline Guizhou & 0.1750 & 0.64 & $-0.2778^{\star}$ & -1.86 \\
\hline Household income & $2.08 \mathrm{E}-06$ & 0.99 & $-3.47 \mathrm{E}-10$ & 0.00 \\
\hline \multicolumn{5}{|l|}{ Life-style factors } \\
\hline Smoking & 0.1542 & 1.26 & $-0.1676^{\star *}$ & -2.05 \\
\hline \multicolumn{5}{|l|}{ Drinking } \\
\hline no drinking & 0.0595 & 0.21 & 0.2694 & 0.40 \\
\hline everyday & -0.1102 & -0.34 & 0.2169 & 0.32 \\
\hline 3-4 times weekly & 0.2763 & 0.81 & 0.2757 & 0.40 \\
\hline 1-2 times weekly & -0.3519 & -0.92 & 0.2448 & 0.36 \\
\hline Less 2 times monthly & -0.3212 & -0.82 & 0.3995 & 0.58 \\
\hline Health exercise & 0.3400 & 1.52 & 0.1660 & 1.23 \\
\hline $\begin{array}{c}\text { Drink water inside } \\
\text { the home }\end{array}$ & 0.1209 & 1.02 & $-0.1469^{\star *}$ & -1.99 \\
\hline $\begin{array}{c}\text { Toilet inside the } \\
\text { home }\end{array}$ & $-0.3483^{* *}$ & -2.49 & 0.0433 & 0.54 \\
\hline $\begin{array}{l}\text { waste nearby the } \\
\text { home }\end{array}$ & -0.0269 & -0.23 & 0.0621 & 0.83 \\
\hline constant & $-2.0081^{* *}$ & -2.50 & $-2.1617^{\star \star}$ & -2.39 \\
\hline Numbers of obs. & 5271 & & 5525 & \\
\hline Log likelihood & -308.5044 & & -870.7965 & \\
\hline LR chi2 (42) & 57.17 & & 264.11 & \\
\hline Prob $>$ chi 2 & 0.0303 & & 0 & \\
\hline Pseudo R2 & 0.0848 & & 0.1317 & \\
\hline
\end{tabular}

Notes: $1 .{ }^{*},{ }^{* *},{ }^{* *}$ : statistical significant in $10 \%, 5 \%, 1 \%$ level. 2 . Coefficient values are estimated marginal effect $(\mathrm{dy} / \mathrm{dx})$ values. 3. Reference group are the age70 and over, the college and over, don't know (health status), Chongqing, don't know (drinking status) groups. Data source: Calculated based on CHNS2000and 2011.

Second, based on the Anderson model, the results showed that the other factors affect health service utilization.

1) Individual characteristic factors affect the probability of health service utilization. For example, the probability of outpatient service utilization is higher in the low-level education (no schooling, primary school) and older groups (70 age and over). The probability of inpatient service utilization is higher for elderly groups (70 age and over) than younger and middle-age groups (age $20-29$, age 30 - 39, age 40 - 49 groups). The probability of receiving a health examination is greater for the high-level education group (college and over) than low and mid- 
dle-level education groups (no schooling, primary school, junior high school, and senior high school ) and elderly groups (70 age and over) than younger and middle-age groups (age 20 - 29, age 30 - 39, age 40 - 49, and age 50 - 59 groups). It is though that the health status is worse for the elderly group than for the younger and middle-age group, therefore the probability of outpatient, inpatient and prevention health service utilization is higher for the elderly group. Moreover, because the high-level education group may have more health information and health care consideration, therefore the probability of receiving health examination is greater for the high-level education group than for the low and middle-education level groups. These results are consistent with the Grossman model (Grossman, 1972) which explains the mechanism of the health care investment behavior.

2) Considering health care demand factors, individuals with poor health and chronic diseases (such as hypertension) are more likely to visit a hospital for outpatient care and receive a health examination. However, the influence of health status on inpatient is not statistically significant, it is found that some patients did not take up hospital admission even though they felt their health status was bad. This may be the result of the financial constraint because a large proportion of the inpatient fee has to be paid by the patient him (her) self or their family and they could not pay for it when ill.

3) In the estimated results for enabling factors, except for the effects of the NCMS which are described above, the coefficients of geographic regions are significant in Estimations (1) (2) and (4). These results show that the status of health care supply, which is different by region, affects health service utilization, particularly for outpatient care and preventative health care. The results indicate that the regional disparity on economic development level and financial affairs may affect the health care supply (e.g. numbers of public hospital, private hospital, doctor, nurse, community health care unit, and the distance from the residence to hospital), which causes the regional disparity of health service utilization. It is an important problem which should be addressed by the Chinese government in the future.

4) As pointed out in previous studies, lifestyle factors affect health service utilization behavior: however, the relationship between the frequency of drinking alcohol and the rate of using health care service is not linear. The possibility of inpatient care is higher in the group with a poor hygiene status, such as not having a toilet at home. It is though that the poor hygiene status may contribute to the higher probability of poor health status. The Chinese government should consider how to improve the poor hygiene status to be found in rural regions.

The results shown in Table 2(a) and Table 2(b) indicated that individual characteristic factors, health care demand factors, enabling factors, Life-style factors affect the health service utilization, these results are consistent with Andersen and Newman (1973), and Andersen (1995). When these factors are controlled, it is clearly that generally the implementation of NCMS did not improve the utilization of health service-including inpatient, outpatient and health ex- 
amination. However, it is thought that the demand of health service and individual characteristics, health status might differ by age groups; the health care expenditure might differ by household income groups; the health service supply and life-style might differ by regional groups. To consider the disparity by groups, we employ a set of robustness check by using subsample as follows.

\subsection{Robustness Check}

1) The Impact of NCMS on Health Service Utilization by Age Groups

Health care status is different by age groups. For example, morbidity and mobility are higher for the elderly group than for the younger group. Therefore, it can be deduced that health service utilization is different by age group. Using sub-samples, the impact of NCMS on health service utilization is estimated by two groups: the age 16 - 49 group and the age 50 and over group. Table 3 shows the results by age groups.

The main findings are as follows. First, the DID items in Estimations (1) (3) and (4) are not statistically significant in the $16-49$ age group and the 50 and over age group. They indicate that there is no difference in health care service utilization (both outpatient and inpatient, inpatient, and health examination)

Table 3. The impact of NCMS on health service utilization by age groups.

\begin{tabular}{|c|c|c|c|c|c|}
\hline & & \multicolumn{2}{|c|}{ (1) Both inpatient and outpatient } & \multicolumn{2}{|c|}{ (2) Outpatient } \\
\hline & & coeff. $(\mathrm{dy} / \mathrm{dx})$ & z-value & coeff. $(\mathrm{dy} / \mathrm{dx})$ & z-value \\
\hline & Treatment & 0.3927 & 1.28 & 0.4692 & 1.50 \\
\hline \multirow[t]{2}{*}{ age $16-49$} & Year & $0.2608^{*}$ & 1.70 & $0.4312^{\star * *}$ & 2.69 \\
\hline & DID & -0.4398 & -1.35 & $-0.5575^{\star}$ & -1.67 \\
\hline \multirow[t]{6}{*}{$\begin{array}{l}\text { age } 50 \text { and } \\
\text { over }\end{array}$} & Treatment & -0.3410 & -0.72 & -3.6254 & -0.68 \\
\hline & Year & 0.2555 & 1.49 & $0.3268^{\star *}$ & 2.16 \\
\hline & DID & 0.2830 & 0.57 & 0.3068 & 0.63 \\
\hline & & \multicolumn{2}{|c|}{ (3) Inpatient } & \multicolumn{2}{|c|}{ (4) Health examination } \\
\hline & & coeff. $(\mathrm{dy} / \mathrm{dx})$ & z-value & coeff. $(\mathrm{dy} / \mathrm{dx})$ & z-value \\
\hline & Treatment & -3.4155 & -0.01 & 0.4356 & 0.83 \\
\hline \multirow[t]{2}{*}{ Age $16-49$} & Year & 0.4937 & 1.21 & $1.0554^{\star * *}$ & 3.97 \\
\hline & DID & 3.0716 & 0.01 & -0.7169 & -1.30 \\
\hline \multirow[t]{3}{*}{$\begin{array}{l}\text { age } 50 \text { and } \\
\text { over }\end{array}$} & Treatment & -3.1743 & -0.02 & -2.6070 & -0.03 \\
\hline & Year & $0.8385^{* *}$ & 2.29 & $0.8016^{* * *}$ & 2.83 \\
\hline & DID & 2.7359 & 0.02 & 2.4055 & 0.03 \\
\hline
\end{tabular}

Notes: $1 .{ }^{*},^{* *}{ }^{* * *}$ : statistical significant in $10 \%, 5 \%, 1 \%$ level. 2 . Coefficient values are estimated marginal effect $(\mathrm{dy} / \mathrm{dx})$ values. 3. Education, gender, self-reported health status, Hypertension, Diabetes, household income, region, smoking, drinking, drink water status, toilet status, waste status are estimated, but these results are not shown in Table 3. Data source: Calculated based on CHNS 2000 and 2011. 
between the NCMS enrollment group and the non-enrollment group. Second, the DID items in Estimation (2) for the 16 - 49 aged group is statistically significant in $10 \%$ level, but the estimated value is negative, which indicates that compared to the NCMS enrollment group, the probability of inpatient care is higher for the non-enrollment group. This may be due to the group that did not participate in the NCMS joining other health insurance schemes (private medical insurance). Based on these results, it can be said that NCMS did not affect the health service utilization in both the age 16 - 49 group and the over 50 age group.

2) The Impact of NCMS on Health Service Utilization by Income Groups

Based on the regulation of NCMS, a part of health care expenditures are paid by the patients themselves, therefore there may be a liquidity constraint problem: the patient could not access health services because they could not pay for it. It is thought the probability of receiving health service may be different by income groups. Using sub-samples, the impact of NCMS on health service utilization is estimated by three income groups: low-income group (first income tertile), middle-level income group (second income tertile), and high-income group (third income tertile). Table 4 shows the results by income group.

The results show that the DID items in Estimations (1) (2) are not statistically significant in the low-income group, middle- and high-income group; The DID items in Estimations (3) (4) are not statistically significant in both the low-income group, and the middle-high income group. These results indicate that even though considering the financial constraints problem by income group, the NCMS did not affect health service utilization.

3) The Impact of NCMS on Health Service Utilization by Regional Groups

Local government operates the NCMS and the central government supports the NCMS funds with subsidies. Because the financial situation differs between local governments the economic development levels are different by regions (for instance, per capita of GDP is higher for the East Region than for the Central and West Regions). Thus, the health service supply and demand may differ by region. To consider these regional disparities, using sub-samples, the impact of NCMS on health service utilization is estimated by three groups: East Region, Central Region and West Region. The results (Table 5) show that the DID items in Estimations (1) (2) are not statistically significant in the East Region, Central Region and West Region groups; The DID items in Estimations (3) (4) are not statistically significant in both the East Region group, and the Central and West Region groups. These results indicate that even to consider the regional disparities, the NCMS did not affect the utilization of health services.

The results of robustness check indicated that even when to consider the disparity by age group, income group, and regional group, the NCMS did not affect the health service utilization in each group. These results are consistent with the results using the total samples (to see Table 2(a) and Table 2(b)).

The main conclusions based on the results including these results of robustness check in the study and the policy implication are summarized in Section 5. 
Table 4. The impact of NCMS on health care service utilization by income groups.

\begin{tabular}{|c|c|c|c|c|c|}
\hline & & \multicolumn{2}{|c|}{$\begin{array}{c}\text { (1) Both inpatient and } \\
\text { outpatient }\end{array}$} & \multicolumn{2}{|c|}{ (2) Outpatient } \\
\hline & & coeff. $(\mathrm{dy} / \mathrm{dx})$ & $z$-value & coeff. $(\mathrm{dy} / \mathrm{dx})$ & z-value \\
\hline \multirow[t]{3}{*}{ Low } & Treatment & 0.2009 & 0.59 & 0.1742 & 0.51 \\
\hline & Year & $0.3211^{* *}$ & 2.21 & $0.4002^{\star * *}$ & 2.65 \\
\hline & DID & -0.2036 & -0.57 & -0.2157 & -0.61 \\
\hline \multirow[t]{3}{*}{ Middle } & Treatment & 0.0083 & 0.02 & 0.1141 & 0.27 \\
\hline & Year & 0.0080 & 0.04 & 0.2587 & 1.19 \\
\hline & DID & -0.0380 & -0.09 & -0.1250 & -0.29 \\
\hline \multirow[t]{5}{*}{ High } & Treatment & -3.3793 & -0.04 & -3.3836 & -0.02 \\
\hline & Year & -0.2946 & -0.46 & -0.3574 & -0.55 \\
\hline & DID & 3.0806 & 0.04 & 3.1916 & 0.02 \\
\hline & & \multicolumn{2}{|c|}{ (3) Inpatient } & \multicolumn{2}{|c|}{ (4) Health examination } \\
\hline & & coeff. $(\mathrm{dy} / \mathrm{dx})$ & z-value & coeff. $(\mathrm{dy} / \mathrm{dx})$ & $z$-value \\
\hline \multirow[t]{3}{*}{ Low } & Treatment & -2.7862 & -0.02 & -2.2929 & -0.02 \\
\hline & Year & $0.7480^{* *}$ & 2.08 & $1.6868^{\star * *}$ & 4.12 \\
\hline & DID & 2.7873 & 0.02 & 1.9835 & 0.02 \\
\hline \multirow{3}{*}{ Middle + High } & Treatment & -3.5408 & -0.02 & 0.2485 & 0.45 \\
\hline & Year & 0.1103 & 0.29 & $0.5790^{*}$ & 1.93 \\
\hline & DID & 2.9547 & 0.02 & -0.5380 & -0.94 \\
\hline
\end{tabular}

Notes: $1 .{ }^{*}, * *, * * *$ statistical significant in $10 \%, 5 \%, 1 \%$ level. 2. Coefficient values are estimated marginal effect $(\mathrm{dy} / \mathrm{dx})$ values. 3. Age, education, gender, self-reported health status, Hypertension, Diabetes, region, smoking, drinking, drink water status, toilet status, waste status are estimated, but these results are not shown in Table 4. 4. Low, middle, and high-income groups are divided by household income first, second and third tertiles. 5. Because the samples is not enough for estimations (3) and (4), the group composed of middle-income group and the high-income group is analyzed as one group. Data source: Calculated based on CHNS 2000 and 2011.

\section{Conclusion}

In China, the NCMS was implemented in 2003 and it is expected that this public health insurance policy would mitigate the inequality of health service utilization in rural regions. Does NCMS affect health service utilization for rural residents? Using the 2000 and 2011 CHNS longitudinal survey data and econometric methods (DID methods), this study conducted an empirical analysis to investigate the impact of NCMS on heath service utilization. The major conclusions are as follows.

First, predisposing factors, enabling factors, health care demand factors, and lifestyle factors affect health care utilization. These results are consistent with Andersen (1995).

Second, results using DID methods indicate that the NCMS did not affect health service utilization (outpatient and inpatient) of individuals when ill; moreover, the NCMS did not increase the probability of receiving a health 
Table 5. The impact of NCMS on health care service utilization by regional groups.

\begin{tabular}{|c|c|c|c|c|c|}
\hline & & \multicolumn{2}{|c|}{ (1) Both inpatient and outpatient } & \multicolumn{2}{|c|}{ (2) Outpatient } \\
\hline & & coeff. $(\mathrm{dy} / \mathrm{dx})$ & z-value & coeff. $(\mathrm{dy} / \mathrm{dx})$ & z-value \\
\hline \multirow[t]{3}{*}{ East } & Treatment & 0.3831 & 1.35 & 0.4102 & 1.45 \\
\hline & Year & $0.4041^{\star *}$ & 2.18 & $0.5200^{* * *}$ & 2.86 \\
\hline & DID & -0.4168 & -1.37 & -0.4445 & -1.48 \\
\hline \multirow[t]{3}{*}{ Central } & Treatment & -3.5817 & -0.02 & -3.2186 & -0.04 \\
\hline & Year & $0.3586^{*}$ & 1.69 & $0.31501^{*}$ & 1.69 \\
\hline & DID & 3.3629 & 0.02 & 3.1333 & 0.04 \\
\hline \multirow[t]{5}{*}{ West } & Treatment & -3.4501 & -0.04 & -3.6454 & -0.02 \\
\hline & Year & -0.1868 & -0.67 & 0.1421 & 0.55 \\
\hline & DID & 3.7380 & 0.04 & 3.8126 & 0.02 \\
\hline & & \multicolumn{2}{|c|}{ (3) Inpatient } & \multicolumn{2}{|c|}{ (4) Health examination } \\
\hline & & coeff. $(\mathrm{dy} / \mathrm{dx})$ & z-value & coeff. $(\mathrm{dy} / \mathrm{dx})$ & z-value \\
\hline \multirow[t]{3}{*}{ East } & Treatment & -3.0874 & -0.01 & 0.2552 & 0.50 \\
\hline & Year & 0.6141 & 1.29 & $0.8966^{* * *}$ & 2.88 \\
\hline & DID & 2.8187 & 0.01 & -0.5550 & -1.01 \\
\hline \multirow{3}{*}{$\begin{array}{c}\text { Central + } \\
\text { West }\end{array}$} & Treatment & -2.5382 & -0.02 & -1.6711 & -0.02 \\
\hline & Year & $-0.6549^{\star}$ & 1.99 & $1.6079^{* * *}$ & 4.62 \\
\hline & DID & 2.1031 & 0.02 & 1.3027 & 0.02 \\
\hline
\end{tabular}

Note: $1 .{ }^{*}, * *, * * *$ statistical significant in $10 \%, 5 \%, 1 \%$ level. 2 . Coefficient values are estimated marginal effect $(\mathrm{dy} / \mathrm{dx})$ values. 3. Age, education, gender, self-reported health status, Hypertension, Diabetes, household income, smoking, drinking, drink water status, toilet status, waste status are estimated, but these results are not shown in Table 5. 4. Because the samples are not enough for estimations (3) and (4), the Central Region group and West Region group is analyzed as one group. Data source: Calculated based on CHNS2000 and 2011.

examination from a long-term perspective.

Why the NCMS did not affect health service utilization even from long-term? The main reasons can be considered as follows. Under the NCMS, patients (mostly inpatients) have to pay the total medical bill first and then apply to the local government for reimbursement. Patients can receive reimbursement (less than $50 \%$ ) only after the local government checks their application documents. Inpatients usually must pay more than $50 \%$ of the total medical expenditures by themselves. In addition, the patients themselves usually pay the entire outpatient fees. It is thought that the high proportion of non-refundable health care charges based on the NCMS might affect health service utilization. However, based on the Urban Basic Employment Health Insurance system (UBEHI) and Urban Basic Resident Health Insurance system (UBRHI) for workers and residents in urban regions, patients only pay $30 \%$ of the medical expenditure by themselves as inpatients. ${ }^{4}$. These differences in the implementation system between the rural and urban regions deserve notice. To resolve health care inequality in rural re-

${ }^{4}$ For the detailed description of UBEHI and UBRHI, please refer Ma (2015) chapter 2. 
gions through the implementation of the NCMS, the proportions of reimbursement by the government should increase. In the future, Chinese government should pay more for the NCMS in rural regions and establish policies to enforce the integration of the different public health insurance systems.

Moreover, although we focus the group with rural registration to test the effect of the NCMS, it is thought the influence may be different between the migrants (labors with the rural registration who live and work in the urban regions) and the rural residents (the group with the rural registration who live and work in the rural regions). Although the migrant group can participate either NCMS or UBEHI, the enrollment rate of UBEHI is low, for example, they are 13.1\% for 2008, 16.9\% for 2012 (Cai \& Wang 2013; Ma 2015). When the migrant who participate the NCMS takes the application for medical expense reimbursement, he (she) has to come back to the local rural region, therefore the positive effect of NCMS on utilizing health service which are provided in urban regions may be disappeared by these complex procedures. The detailed empirical study focus on the effect of public health insurance system for the migrant group should be done in the future.

Lastly, it is thought except the public health insurance, the factors of health care supply side (e.g. the distance to the nearest hospital or clinic, the private and public hospital allocation, the government pharmaceutical price system), and factors of individual preference (e.g. risk aversion, time preference) should affect the utilization of health care service. Although we cannot gain more information for these factors from CHNS, these issues also should be discussed.

\section{Funding}

This research was supported by a project grant from JSPS KAKENHI Grant Number JP16K03611 and Grant Number 26380297.

\section{References}

Andersen, R. (1995). Revisiting the Behavioral Model and Access to Medical Care: Does It Matter? Journal of Health and Social Behavior, 36, 1-10. https://doi.org/10.2307/2137284

Andersen, R., \& Newman, J. F. (1973). Societal and Individual Determinants of Medical Care Utilization in the United States. The Milbank Memorial Fund Quarterly. Health and Society, 51, 95-124. https://doi.org/10.2307/3349613

Card, D., Dobkin, C., \& Maestas, N. (2008). The Impact of Nearly Universal Insurance Coverage on Health Care Utilization and Health: Evidence from Medicare. American Economic Review, 98, 2242-2258.

http://www.aeaweb.org/articles.php?doi=10.1257/aer.98.5.2242 https://doi.org/10.1257/aer.98.5.2242

Cheng, L., Liu, H., Zhang, Y., Shen, K., \& Zeng, Y. (2015). The Impact of Health Insurance of Health Outcomes and Spending of the Elderly: Evidence from China's New Cooperative Medical Scheme. Health Economics, 24, 672-691.

https://doi.org/10.1002/hec.3053

Currie, J., \& Gruber, J. (1996a). Health Insurance Eligibility, Utilization of Medical Care and Child Health. Quarterly Journal of Economics, 111, 431-466. 
http://www.jstor.org/stable/2946684

https://doi.org/10.2307/2946684

Currie, J., \& Gruber, J. (1996b). Saving Babies: The Efficacy and Cost of Recent Changes in the Medicaid Eligibility of Pregnant Women. Journal of Political Economy, 104, 1263-1296. http://www.jstor.org/stable/2138939 https://doi.org/10.1086/262059

Currie, J., \& Gruber, J. (1997). The Technology of Birth: Health Insurance, Medical Interventions and Infant Health. Working Paper 5985, Cambridge, MA: National Bureau Economic Research. https://doi.org/10.3386/w5985

Currie, J., Decker, S., \& Lin, W. (2008). Has Public Health Insurance for Older Children Reduced Disparities in Access to Care and Health Outcomes? Journal of Health Economics, 27, 1567-1581.

Decker, S. L., \& Remler, D. K. (2004). How Much Might Universal Health Insurance Reduce Socioeconomic Disparities in Health? A Comparison of the US and Canada. Applied Health Economics and Health Policy, 3, 205-216. https://doi.org/10.2165/00148365-200403040-00004

Finkelstein, A., \& McKnight, R. (2008). What Did Medicare Do? The Initial Impact of Medicare on Mortality and Out of Pocket Medical Spending. Journal of Public Economics, 92, 1644-1668.

Gakidou, E., Lozano, R., Gonzalez-Pier, E., Abbott-Klafter, J., Barofsky, J. T., Bryson-Cahn, C., Feehan, D. M., Lee, D. K., Hernandez-Llamas, H., \& Murray, C. J. (2006). Assessing the Effect of the 2001-06 Mexican Health Reform: An Interim Report Card. The Lancet, 368, 1920-1935. https://doi.org/10.1016/S0140-6736(06)69568-8

Gao, J., Raven, J. H., \& Tang, S. (2007). Hospitalisation among the Elderly in Urban China. Health Policy, 84, 210-219. https://doi.org/10.1016/j.healthpol.2007.03.007

Grossman, M. (1972). On the Concept of Health Capital and the Demand for Health. Journal of Political Economy, 80, 223-255. http://www.jstor.org/stable/1830580 https://doi.org/10.1086/259880

Hsiao, W. C. (1984). Transformation of Health in China. The New England Journal of Medicine, 310, 932-936. https://doi.org/10.1056/NEJM198404053101428

Jowett, M., Deolalikar, A., \& Martinsson, P. (2004). Health Insurance and Treatment Seeking Behavior: Evidence from a Low-Income Country. Health Economics, 13, 845-857. https://doi.org/10.1002/hec.862

Lei, X., \& Lin, W. (2009). The New Cooperative Medical Scheme in Rural China: Does More Coverage Mean More Service and Better Health? Health Economics, 18, S25-S46. https://doi.org/10.1002/hec.1501

Li, X., \& Zhang, W. (2013). The Impacts of Health Insurance on Health Care Utilization among the Older People in China. Social Science and Medicine, 85, 59-65.

Li, Y., Wu, Q., Liu, C., Kang, Z., Xie, X., Yin, H., Jiao, M., Liu, G., Hao, Y., \& Ning, N. (2014). Catastrophic Health Expenditure and Rural Household Impoverishment in China: What Role Does the New Cooperative Health Insurance Scheme Play? PLoS ONE, 9, e93253. https://doi.org/10.1371/journal.pone.0093253

Liu, Y. L. (2004). Development of the Rural Health Insurance System in China. Health Policy and Planning, 19, 159-165. https://doi.org/10.1093/heapol/czh019

Liu, Y., Hsiao, W. C. L., Li, Q., Liu, X., \& Ren, M. (1995). Transformation of China's Rural Health Insurance Financing. Social Science and Medicine, 41, 1085-1093.

Lu, C., Liu, Y., \& Shen, J. (2012). Does China's Rural Cooperative Medical System Achieve Its Goals? Evidence from the China Health Surveillance Baseline Survey in 2001. Contemporary Economic Policy, 30, 93-112. 
http://onlinelibrary.wiley.com/journal/10.1111/\%28ISSN\%291465-7287 https://doi.org/10.1111/j.1465-7287.2011.00252.x

Lu, S., \& Zhang, D. (2013). China's New Rural Cooperative Medical Scheme and Underutilization of Medical Care among Adults over 45: Evidence from CHARLS Pilot Data. The Journal of Rural Health, 29, s51-s61. https://doi.org/10.1111/jrh.12013

Ma, X. (2015). Public Health Insurance System Reform in China. Kyoto: Kyoto University Press.

Ma, X. (2016). The Effects of New Cooperation Medicine Scheme on the Utilization of Health Care Service in Rural China. Journal of Statistical Science and Application, 4, 119-131.

Panopoulu, G., \& Velez, C. (2001). Subsidized Health Insurance, Proxy Means Testing and the Demand for Health Care among the Poor in Colombia. Colombia Poverty Report Volume II, Washington DC: World Bank.

Sepehri, A., Sarma, S., \& Simpson, W. (2006). Does Non-Profit Health Insurance Reduce Financial Burden? Evidence from the Vietnam Living Standards Survey Panel. Health Economics, 15, 603-616. https://doi.org/10.1002/hec.1080

Shi, W., Chongsuvivatwong, V., Geater, V., Zhang, J., Zhang, H., \& Brombal, D. (2010). The Influence of the Rural Health Security Schemes on Health Utilization and Household Impoverishment in Rural China: Data from a Household Survey of Western and Central China. International Journal for Equity in Health, 9, 7.

https://doi.org/10.1186/1475-9276-9-7

Trujillo, A. J., Portillo, J. E., \& Vernon, A. (2005). The Impact of Subsidized Health Insurance for the Poor: Evaluating the Colombian Experience Using Propensity Score Matching. International Journal of Health Care Finance and Economics, 5, 211-239. http://www.jstor.org/stable/25067725 https://doi.org/10.1007/s10754-005-1792-5

Wagstaff, A., \& Lindelow, M. (2008). Can Insurance Increase Financial Risk? The Curious Case of Health Insurance in China. Journal of Health Economics, 27, 990-1005.

Wagstaff, A., Lindelow, M., Gao, J., Xu, L., \& Qian, J. (2009). Extending Health Insurance to the Rural Population: An Impact Evaluation of China's New Cooperative Medical Scheme. Journal of Health Economics, 28, 1-19.

Wagstaff, A., Winnie, Y., Lindelow, M., \& Hsiao, W. C. (2009). China's Health System and Its Reform: A Review of Recent Studies. Health Economics, 18, S7-S23. https://doi.org/10.1002/hec.1518

You, X., \& Kobayashi, Y. (2011). Determinants of Out-of-Pocket Health Expenditure in China. Application Health Economic Health Policy, 9, 39-49. http://link.springer.com/journal/volumesAndIssues/40258 https://doi.org/10.2165/11530730-000000000-00000 


\section{Appendix}

Table A1. Summary of previous studies.

\begin{tabular}{|c|c|c|c|}
\hline Author & Year & Data & Model \\
\hline $\mathrm{Ma}$ & 2016 & $\begin{array}{l}\text { 2000, 2004, } 2006 \text { CHNS } \\
\text { (China Health and } \\
\text { Nutrition Survey) }\end{array}$ & $\begin{array}{l}\text { DID, Probit regression } \\
\text { model }(\mathrm{RE})\end{array}$ \\
\hline Shi and Zhang & 2013 & $\begin{array}{l}2008 \text { CHARLS (China } \\
\text { Health and Retirement } \\
\text { Longitudinal Study) }\end{array}$ & Logistic regression model \\
\hline Li and Zhnag & 2013 & 2008 CHARLS, & Two-part model \\
\hline $\begin{array}{l}\mathrm{Xu} \text {, Zhang } \\
\text { and Ji }\end{array}$ & 2013 & 2004, 2009 CNHS & DID \\
\hline Peng and Qing & 2015 & 2000, 2004, 2006, 2009 CNHS & First difference model \\
\hline Lei & 2009 & 2000, 2004, 2006 CHNS & Fixed-effect model, IV, DID \\
\hline $\begin{array}{l}\text { Wagstaff, } \\
\text { Lindelow }\end{array}$ & 2008 & 1991, 1993, 1997, 2000 CHNS & Logistic regression, IV, FE \\
\hline Wagstaff & 2009 & $\begin{array}{c}2003 \text { NHSS (National Health } \\
\text { Service Survey) }\end{array}$ & $\begin{array}{l}\text { Probit regression model (IV), } \\
\text { GLM (IV), Logistic } \\
\text { regression (FE) }\end{array}$ \\
\hline Shi & 2010 & 2008 survey data & Logistic regression model \\
\hline Xiao & 2010 & 2008.12-2009.3 survey data & Logistic regression model \\
\hline Luo, Han & 2011 & $\begin{array}{c}\text { 1991, 1993, 1997, 2000, 2004, } \\
2006 \text { CHNS }\end{array}$ & $\begin{array}{l}\text { Logistic regression model, } \\
\text { IV, FE }\end{array}$ \\
\hline You, Kobayashi & 2011 & 2004 CHNS & Heckman two-step model \\
\hline $\mathrm{Lu}$ & 2012 & $\begin{array}{l}2011 \text { CHSS (China Health } \\
\text { Surveillance Baseline) }\end{array}$ & PSM, IV \\
\hline Jing & 2013 & 2006,2008 survey data & DID \\
\hline Cheng & 2014 & $\begin{array}{l}\text { 2005, } 2008 \text { CLHLS (Chinese } \\
\text { Longitudinal Healthy } \\
\text { Longevity Survey) }\end{array}$ & PSM \\
\hline $\mathrm{Li}$ & 2014 & 2008 NHSS & Logistic regression model \\
\hline
\end{tabular}

Source: based on authors. Note: IV: instrument variable methods. PSM: propensity score matching. DID: difference in difference method. RE: random-effect. FE: fixed effect. 
Submit or recommend next manuscript to SCIRP and we will provide best service for you:

Accepting pre-submission inquiries through Email, Facebook, LinkedIn, Twitter, etc. A wide selection of journals (inclusive of 9 subjects, more than 200 journals)

Providing 24-hour high-quality service

User-friendly online submission system

Fair and swift peer-review system

Efficient typesetting and proofreading procedure

Display of the result of downloads and visits, as well as the number of cited articles Maximum dissemination of your research work

Submit your manuscript at: http://papersubmission.scirp.org/

Or contact chnstd@scirp.org 